\title{
Enzyme encapsulation in glycerol-silicone membranes for bioreactions and biosensors
}

\author{
Mazurek, Piotr; Zelisko, Paul M.; Skov, Anne L.; A. Brook, Michael
}

Published in:

ACS Applied Polymer Materials

Link to article, DOI:

10.1021/acsapm.9b01082

Publication date:

2020

Document Version

Peer reviewed version

Link back to DTU Orbit

Citation (APA):

Mazurek, P., Zelisko, P. M., Skov, A. L., \& A. Brook, M. (2020). Enzyme encapsulation in glycerol-silicone membranes for bioreactions and biosensors. ACS Applied Polymer Materials, 2(3), 1203-1212.

https://doi.org/10.1021/acsapm.9b01082

\section{General rights}

Copyright and moral rights for the publications made accessible in the public portal are retained by the authors and/or other copyright owners and it is a condition of accessing publications that users recognise and abide by the legal requirements associated with these rights.

- Users may download and print one copy of any publication from the public portal for the purpose of private study or research.

- You may not further distribute the material or use it for any profit-making activity or commercial gain

- You may freely distribute the URL identifying the publication in the public portal

If you believe that this document breaches copyright please contact us providing details, and we will remove access to the work immediately and investigate your claim. 
Article

\section{Enzyme encapsulation in glycerol-silicone \\ membranes for bioreactions and biosensors}

Piotr Mazurek, Paul M Zelisko, Anne Ladegaard Skov, and Michael A Brook

ACS Appl. Polym. Mater., Just Accepted Manuscript • DOI: 10.1021/acsapm.9b01082 • Publication Date (Web): 11 Feb 2020

Downloaded from pubs.acs.org on February 18, 2020

\section{Just Accepted}

"Just Accepted" manuscripts have been peer-reviewed and accepted for publication. They are posted online prior to technical editing, formatting for publication and author proofing. The American Chemical Society provides "Just Accepted" as a service to the research community to expedite the dissemination of scientific material as soon as possible after acceptance. "Just Accepted" manuscripts appear in full in PDF format accompanied by an HTML abstract. "Just Accepted" manuscripts have been fully peer reviewed, but should not be considered the official version of record. They are citable by the Digital Object Identifier (DOI®). "Just Accepted" is an optional service offered to authors. Therefore, the "Just Accepted" Web site may not include all articles that will be published in the journal. After a manuscript is technically edited and formatted, it will be removed from the "Just Accepted" Web site and published as an ASAP article. Note that technical editing may introduce minor changes to the manuscript text and/or graphics which could affect content, and all legal disclaimers and ethical guidelines that apply to the journal pertain. ACS cannot be held responsible for errors or consequences arising from the use of information contained in these "Just Accepted" manuscripts. 


\title{
Enzyme encapsulation in glycerol-silicone membranes for bioreactions and biosensors
}

\author{
Piotr Mazurek ${ }^{a, c}$, Paul M. Zelisko ${ }^{b}$, Anne L. Skova ${ }^{*}$, Michael A. Brook \\ a Danish Polymer Centre, Department of Chemical Engineering, Technical University of \\ Denmark, Kgs. Lyngby, 2800, Denmark. \\ b Department of Chemistry and Centre for Biotechnology, Brock University, St. Catharines, \\ Ontario, L2S 3A1, Canada. \\ c Department of Chemistry and Chemical Biology, McMaster University, Hamilton, \\ Ontario, L8S 4M1, Canada. \\ *Corresponding author: al@kt.dtu.dk
}

Keywords: enzyme, encapsulation, silicone, membrane, biosensor

\begin{abstract}
Efficient enzyme immobilization is one of the main challenges in biocatalysis. Properly immobilized enzymes ensure enzyme reusability and high conversion efficiency of biocatalytic reactions, which ultimately leads to reduction of the process costs and increased sustainability. Here a simple, versatile and cost-efficient platform technology for physical encapsulation of enzymes within elastomeric membranes is presented. The membranes are obtained by simple mixing of two immiscible liquids, a commercial silicone prepolymer and glycerol, which results in formation of glycerol-in-silicone emulsions. Upon curing of the
\end{abstract}


silicone phase free-standing elastomers are obtained, and the glycerol droplets are randomly dispersed in the silicone matrix. Enzymes are dissolved in the glycerol phase prior to the emulsification process, thus each glycerol reservoir of the glycerol-silicone membrane becomes a micro-size bioreactor. In a simple experiment an enzyme-containing glycerolsilicone membrane was immersed in water with dissolved substrate of a bioreaction. The concentration gradient induces the migration of the substrate to the glycerol reservoirs where it is converted by the enzyme to a product, which is subsequently released from the membrane. In this manuscript the performance of processes involving diffusion and enzymatic reactions within the glycerol-silicone membranes are compared. The glycerol content in the membranes was found to have a significant impact on the reaction rate. This concept was also utilized to create a proof-of-concept elastomeric colorimetric glucose biosensor.

\section{Introduction}

The industrial use of enzymes is often limited by the fact that they dissolve in aqueous media, such that they are eventually lost and/or denature, which inevitably leads to decreases in process efficiency and increasing process costs. ${ }^{1}$ Enzyme immobilization dramatically improves the stability of the biomolecules. ${ }^{2-8}$ Typically, enzyme immobilization is divided into five categories: (i) non-covalent adsorption, (ii) immobilization through ionic interactions, (iii) covalent attachment, (iv) cross-linking of an enzyme, and (v) entrapment (in this work the terms entrapment and encapsulation are used synonymously). ${ }^{9}$ While the first two strategies are the most straightforward, the enzymes are not permanently attached to a support and so enzyme leaching remains a concern and a general loss of activity is still expected. ${ }^{10,11}$ Covalent attachment usually ensures an excellent degree of immobilization, however, this method is often expensive, time consuming, and requires chemical 
modification of the enzyme, which may lead to a loss of enzyme activity. ${ }^{12,13}$ Cross-linking enzymes is a very efficient immobilization technique that eliminates issues associated with a support material, but it requires exceptional enzyme purity and is usually accompanied by a decrease in enzyme activity. ${ }^{14,15}$

Many of the issues noted above can be addressed by entrapping enzymes in a matrix from which they cannot readily escape, but through which small molecule substrates and products readily pass. Classical enzyme entrapment involves embedding enzymes within a polymer matrix. ${ }^{14-17}$ This type of immobilization is technologically straightforward. However, embedded enzymes are often reported to suffer from meager substrate binding efficiencies and hence product formation. ${ }^{15}$ Enzyme entrapment within hollow carriers, such as mesoporous microcapsules, is technologically more challenging, however, it overcomes many of the issues associated with classical enzyme entrapment. ${ }^{15,18-20}$ The sol-gel method is by far the most frequently applied method of this type and enzymes have been reported to exhibit the same, or even enhanced, activity and increased life-times compared to free enzymes. ${ }^{21-24}$ With this technique enzymes are enclosed within a semi-permeable shell that has the capacity to protect the enzymes from harsh environmental conditions such as extremes of temperature, mechanical stress, or $\mathrm{pH}$. The method does not require chemical modification of the enzyme. ${ }^{14,21}$ Moreover, it is possible to tune the content of the capsule, which facilitates the ability to create multi-enzyme systems, encapsulation of living cells and microorganisms, as well as ensuring a favorable microenvironment for the biocatalysts. ${ }^{25,26}$

Glycerol and silicone pre-polymers are two virtually immiscible liquids. When formulated as an emulsion, the glycerol phase is evenly dispersed within the silicone pre-polymer continuous phase. Free-standing silicone elastomers with incorporated glycerol droplets are 
obtained upon cross-linking of the silicone pre-polymer. ${ }^{27,28}$ Interestingly, the mechanical properties of these composites are not compromised as the glycerol loading increases, even when the total weight fraction of glycerol is as high as $55 \mathrm{wt} \%$ (we characterize these materials throughout the paper as "per hundred weight rubber" (phr). For example, $55 \mathrm{wt} \%$ of glycerol represents $120 \mathrm{phr}^{27}$ ). Preliminary studies (data not shown) confirmed that other liquids, in particular water, or buffered solutions, cannot be used in a similar fashion mainly as a result of high vapor pressure leading to the rapid loss of the encapsulated liquid from the membrane, even at room temperature. Moreover, water and silicone do not form stable emulsions without surfactants, addition of which carries a substantial risk of enzyme denaturation. ${ }^{29}$ The glycerol-silicone elastomers can be successfully shaped into bulk samples, foams, and membranes as thin as $50 \mu \mathrm{m} .{ }^{30}$ Recently it was reported that the glycerol-silicone membranes can be utilized as drug delivery materials. ${ }^{31}$ Bioactive, small molecules were incorporated into the glycerol phase of the membrane. Upon exposure to an aqueous environment the material released the bioactive substances and the rate of the release could be controlled by adjusting the glycerol loading. Additionally, the influence of water on the molecular diffusivity was thoroughly explained. ${ }^{31}$ It was argued that small molecules diffuse out of the membranes significantly faster than large molecules. Given these observed behaviors for small and large molecules, could the glycerol-silicone elastomers become a platform for enzyme immobilization and thus for hosting biochemical reactions?

Enzyme-silicone interactions have been studied by various groups. However, the nature of these interactions is not fully understood. ${ }^{29,32,33}$ Various groups have confirmed that hydrophobic surfaces can have a very positive impact on the reactivity of various enzymes, particularly lipases. ${ }^{9,34}$ The activity of enzymes in water-in-silicone emulsions has also been studied. ${ }^{29,35,36}$ The emulsion systems containing enzymes showed equal or enhanced enzyme 
The idea of entrapping enzymes within glycerol-silicone elastomers brings several advantages over enzyme-containing water-in-silicone emulsions, such as negligible evaporation of the dispersed phase, additional enzyme stabilization provided by glycerol, and no need to use surfactants, which can denature enzymes. Moreover, the proposed entrapment method makes the enzymes more readily available for bioreactions compared to entrapment within a silicone matrix in that the enzyme is already dissolved within the glycerol phase. Additionally, the silicone layer separating glycerol domains is very thin (down to fractions of a micrometer), thus allowing for relatively fast mass transport. The listed examples suggest that glycerol-silicone membranes will be good candidates for enzyme immobilization.

The aim of the work was to create a versatile and cost-efficient platform for enzyme immobilization that tackles the main disadvantage of the classical enzyme entrapment - poor diffusivity of substrates and products of enzymatic reactions. Such solid materials would be particularly useful for both high throughput analyses in the field, and for topical applications, including on human skin, providing a non-invasive option for monitoring glucose levels. The beneficial features of sol-gel encapsulation are combined with the inherent softness, 
robustness, and high permeability of silicone elastomers and the drug releasing capabilities of glycerol-silicone membranes. ${ }^{42}$ The glycerol domains of the glycerol-silicone elastomers are shown to act as hosts for enzymes and enzymatic reactions while the silicone acts as a semipermeable membrane allowing for substrate and product transport.

\section{Experimental}

\subsection{Materials}

A two-component addition-cured Sylgard 184 (S184) silicone elastomer kit was purchased from Dow Corning, (Midland, Michigan, USA). Karstedt's catalyst - platinum(0) 1,3divinyl-1,1,3,3-tetramethyldisiloxane complex; $2 \%$ solution in xylene - was obtained from Gelest (Morrisville, Pennsylvania, USA). Glycerol, trypsin Type I from bovine pancreas (TRY, E.C. 3.4.21.4, lyophilized powder, 10,000 BAEE U/mg), $\alpha$-chemotrypsin Type II from bovine pancreas (CHT, E.C. 3.4.21.1, lyophilized powder, $40 \mathrm{U} / \mathrm{mg}$ ), glucose oxidase from Aspergillus niger (GOx, E.C. 1.1.3.4, lyophilized powder, $149.5 \mathrm{U} / \mathrm{mg}$ ), horseradish peroxidase (HRP, E.C. 1.11.1.7, lyophilized powder, $283 \mathrm{U} / \mathrm{mg}$ ), $N_{\alpha}$-benzoyl-L-arginine ethyl ester hydrochloride (BAEE), N-benzoyl-L-tyrosine ethyl ester (BTEE), fluorescein-5isothiocyanate (FITC), sodium bicarbonate, dimethylformamide (DMF), hydroxylamine, sodium hydroxide, iodine, potassium iodide, glucose, D-(+)-trehalose dihydrate, sodium citrate dihydrate, citric acid and filtration medium Sephadex G-25 were purchased from Sigma Aldrich. All chemicals were used as received.

\subsection{General route for sample preparation, shown for G80(CHT-0.5)}

Nomenclature: G80(CHT-0.5) - G80 stands for glycerol and amount of glycerol (80 weight parts of glycerol per 100 weight parts of silicone rubber (phr) composition including polymer, 
cross-linker, fillers and other additives), and CHT-0.5 corresponds to the incorporated enzyme (chymotrypsin) and its amount in glycerol presented in $\mathrm{wt} \%$.

Preparation: In a typical experiment chymotrypsin $(4.5 \mathrm{mg}, 180 \mathrm{nmol})$ was first dissolved in deionized (DI) water $(50 \mu \mathrm{L})$, which was followed by the addition of glycerol $(0.9 \mathrm{~g}, 9.8$ mmol). Subsequently, the S184 base $(1.023 \mathrm{~g}$ containing an extra $100 \mathrm{ppm}, 0.24 \mu \mathrm{mol}$ of Karstedt's catalyst) and S184 curing agent (0.102 g) were added. The composition was handstirred for $20 \mathrm{~s}$ with a spatula and subsequently mixed for $1 \mathrm{~min}$ at 3500 revolutions per minute (rpm) using a dual asymmetric centrifuge SpeedMixer DAC 150 FVZ-K. The quantity of Karstedt's catalyst was optimized to ensure rapid and efficient cross-linking of the silicone matrix at room temperature. The resulting glycerol-in-silicone emulsion was evenly coated onto a transparent cellulose acetate support film using a commercial coating knife (Elcometer 3540 Bird Film Applicator: $50 \mathrm{~mm}, 50-100-150-200 \mu \mathrm{m}$ ). The samples were cured overnight at room temperature after which time the free-standing and stretchable 100 $\mu \mathrm{m}$ thick films were obtained.

Samples containing an enzymatic glucose assay were prepared using the protocol described above. A typical formulation contained GOx (3 mg, $18.8 \mathrm{nmol})$ and HPR (0.5 mg, $11.4 \mathrm{nmol})$ dissolved in citrate buffer $(50 \mu \mathrm{L}, 50 \mathrm{mM}, \mathrm{pH}$ 6) and mixed with a mixture $(0.9 \mathrm{~g})$ containing: glycerol $(0.75 \mathrm{~g}, 8.1 \mathrm{mmol}), \mathrm{KI}(75 \mathrm{mg}, 0.45 \mathrm{mmol})$, and trehalose $(75 \mathrm{mg}, 0.20$ mmol). The obtained solution was then placed in the SpeedMixer with the S184 base (1.023 g, containing an extra $100 \mathrm{ppm}, 0.24 \mu \mathrm{mol}$ of Karstedt's catalyst) and S184 curing agent $(0.102 \mathrm{~g})$.

Other composites were prepared using different ratios of constituents, as shown in Table 1.

Table 1. List of investigated samples in chronological order to their occurrence in the manuscript. ${ }^{\mathrm{a}}$ 


\begin{tabular}{|c|c|c|c|c|}
\hline No & Sample name & $\begin{array}{c}\text { Glycerol } \\
\text { loading }^{\mathrm{b}}[\mathrm{ph} \mathrm{r}]\end{array}$ & $\begin{array}{l}\text { Amount of enzyme in } \\
\% \text { of glycerol }\end{array}$ & $\begin{array}{c}\text { Other substances as \% of } \\
\text { glycerol }\end{array}$ \\
\hline 1 & G80(FITC-CHT) & 80 & FITC-CHT ${ }^{\mathrm{c}}$ & (2) \\
\hline 2 & G120(FITC-CHT) & 120 & FITC-CHT ${ }^{c}$ & - \\
\hline 3 & G40 & 40 & - & - \\
\hline 4 & G80 & 80 & - & - \\
\hline 5 & G120 & 120 & - & - \\
\hline 6 & G40(TR-EQ) & 40 & $\mathrm{TR}-0.78$ & $\mathrm{H}_{2} \mathrm{O}-8.6$ \\
\hline 7 & G80(TR-EQ) & 80 & $\mathrm{TR}-0.50$ & $\mathrm{H}_{2} \mathrm{O}-5.6$ \\
\hline 8 & G120(TR-EQ) & 120 & $\mathrm{TR}-0.41$ & $\mathrm{H}_{2} \mathrm{O}-4.5$ \\
\hline 9 & G80(CHT-0.5) & 80 & CHT -0.5 & $\mathrm{H}_{2} \mathrm{O}-5.6$ \\
\hline 10 & G80(GSGA) & 80 & $\begin{array}{l}\text { GOx }-0.4, \quad \text { HRP }- \\
0.067\end{array}$ & $\mathrm{TH}-10, \mathrm{KI}-10$, buffer -6.7 \\
\hline 11 & G120(GSGA) & 120 & $\begin{array}{l}\text { GOx }-0.4, \text { HRP }- \\
0.067\end{array}$ & $\mathrm{TH}-10, \mathrm{KI}-10$, buffer -4.4 \\
\hline
\end{tabular}

a More information on sample compositions can be found in the Supporting Information, Table S1.

b Sylgard 184 was used as a silicone matrix for each of the samples therefore it is not included in the sample name.

${ }^{\mathrm{c}}$ A known amount of FITC-CHT water solution was added to glycerol.

\subsection{Protein labeling with FITC}

Protein labeling was carried out according to a procedure described by Zelisko et al. ${ }^{35}$ In short, CHT (12.8 mg, $0.512 \mathrm{nmol})$ was dissolved in $1 \mathrm{~mL}$ of a sodium bicarbonate buffer $(\mathrm{pH}$ 8.5). Subsequently FITC (100 mg, $0.257 \mathrm{mmol}$, used in excess over CHT) dissolved in DMF $(10 \mathrm{~mL})$ was added. The reaction was carried out for $1 \mathrm{~h}$ at room temperature after which 0.1 $\mathrm{mL}$ of a hydroxylamine solution (prepared by dissolving $1.05 \mathrm{mg}$ of hydroxylamine in $5 \mathrm{~mL}$ in DI water and subsequent dilution by adding $5 \mathrm{~mL}$ of DI water) was added in order to bind any unreacted FITC. The CHT labeled with FITC (referred to as FITC-CHT) was purified on a 10x300 mm column charged with Sephadex G-25.

\subsection{Instrumentation}

A Tecan Safire microplate reader from MTX Lab Systems was used to evaluate the immobilization efficiency of FITC-labeled enzymes. Progress of enzymatic reactions was 
monitored using the Vernier UV-VIS Spectrophotometer and the Logger Pro 3.10.2 software package. Sample morphology (200-300 $\mu \mathrm{m}$ thick specimens were investigated) was evaluated using a Tescan Vega II LSU scanning electron microscope (SEM) operating at $20 \mathrm{kV}$. An approximately $15 \mathrm{~nm}$ thick gold layer was deposited onto the samples using Polaron E5100 sputter coater. Note the morphologies of 'thinner' $\sim 100 \mu \mathrm{m}$ and 'thicker' $200-300 \mu \mathrm{m}$ samples were found to be the same (data not shown). The image processing and analysis tool Image J was used to perform color analysis.

\section{Results and discussion}

\subsection{Efficiency of enzyme immobilization and mechanism of enzymatic reactions mediated by glycerol-silicone membranes}

Previously, it was demonstrated that the release of the relatively small molecule hydroquinone from glycerol-silicone membranes was facile when the sample was exposed to water. ${ }^{31}$ It is notable that glycerol is also released slowly from the membranes as described previously and additionally proved in the Supporting Information, Figure S1. ${ }^{27} \mathrm{We}$ hypothesized that the release rate from such matrices should strongly depend on the size of the substance under investigation, and should be significantly slower in the case of large molecules, such as enzymes, due to physical hindrances. This hypothesis was tested by examining the efficiency of enzyme immobilization within the glycerol domains.

a-Chymotrypsin was labeled with FITC (to give FITC-CHT) in order to increase detection accuracy using fluorescence during the study on enzyme immobilization efficiency; a corresponding study performed using the unmodified enzyme did not yield any conclusive information. A known amount of the FITC-CHT aqueous solution was added to glycerol that was used subsequently to prepare the glycerol-silicone membrane following the protocol 
described in Section 2.2. The efficiency of enzyme immobilization was evaluated by immersing the enzyme-containing glycerol-silicone membranes $\left(20 \mathrm{~cm}^{2}\right.$ in area and $0.1 \mathrm{~mm}$ thick) in $20 \mathrm{~mL}$ of DI water for $24 \mathrm{~h}$ after which time fluorescence of the water solution was examined and compared to the signal (excitation $495 \mathrm{~nm}$, emission maximum $520 \mathrm{~nm}$ ) of a reference sample. The elastomer made with $80 \mathrm{phr}$ of glycerol released only $1.7 \%$ of the total protein content, while the sample with $120 \mathrm{phr}$ of glycerol released $13.0 \%$. The obtained results are in a good agreement with the results reported previously ${ }^{31}$ in that the release rate from the glycerol-silicone elastomers correlated with increases in glycerol loading. Samples with high glycerol content are separated by thinner silicone domains, thus the release rate is enhanced. Perhaps more importantly, samples with $120 \mathrm{phr}$ of glycerol are bicontinuous in nature, which should facilitate substrate migration through hydrophilic channels alone (more information about the formation of the bicontinuous structure can be found in the Supporting Information, Section S2). ${ }^{31}$ As a consequence, the samples with higher glycerol loadings (about $120 \mathrm{phr}$ ) appear less applicable for enzymatic processes conducted in aqueous media, as the enzyme entrapment is significantly less efficient compared to the sample with moderate ( $80 \mathrm{phr})$ glycerol content.

These data suggested the possibility of using the glycerol droplets as a series of connected microreactors. The concept of utilizing the glycerol-silicone elastomers to perform enzymatic reactions is schematically presented in Figure 1. Enzymes were physically immobilized within the glycerol domains of the membrane and the domains became hosts for enzymatic reactions. The membranes were then immersed in an aqueous environment containing the reaction substrate which migrated into the enzyme-containing glycerol domains where the biocatalytic reaction took place. Subsequently, the reaction products were discharged from the membrane, thus accomplishing the enzymatic reaction process. 


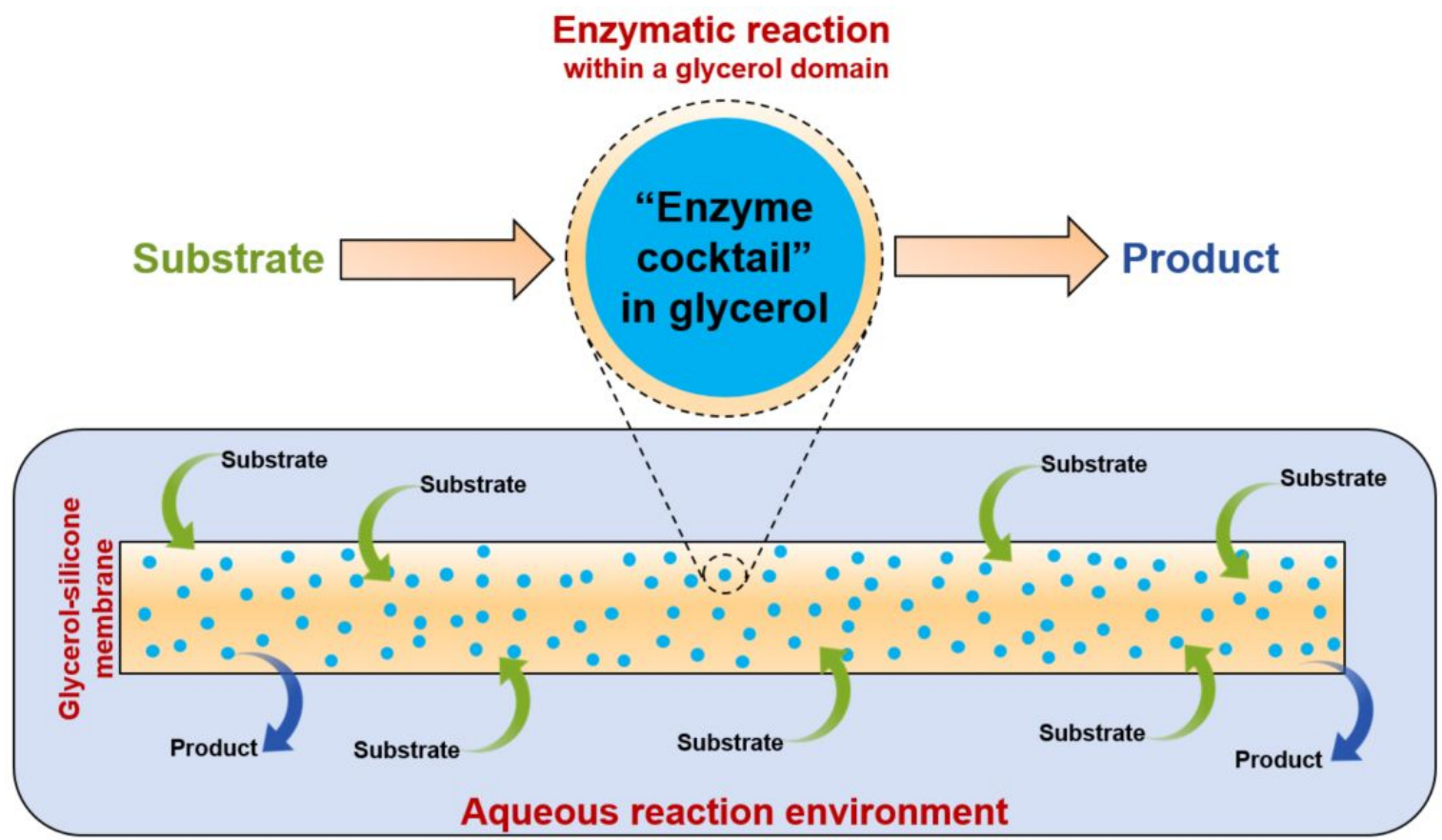

Figure 1. Schematic illustration of physical and biochemical processes taking place in the glycerol-silicone membranes. Substrates dissolved in the aqueous reaction environment migrate into the enzyme-containing glycerol domains where the enzymatic reaction takes place. The products are subsequently released from the membrane driven by a concentration gradient between the glycerol domains and the aqueous reaction environment.

\subsection{Nature and morphology of the glycerol-silicone membranes and mobility of small molecules through the membranes}

The migration of substances from within the glycerol-silicone materials to an external aqueous environment is possible and is driven by diffusion. ${ }^{31}$ It was presumed that this factor would also trigger migration of substances through glycerol domains within a glycerolsilicone specimen provided there is a concentration difference of the substance between droplets. To examine this hypothesis, a simple experiment was designed in which $150 \mu \mathrm{L}$ 
droplet of $5 \% \mathrm{I}_{3} \mathrm{~K}$ solution was placed on each of the three glycerol-silicone membranes containing 40, 80 and $120 \mathrm{phr}$ of glycerol. Subsequently, a $50 \mu \mathrm{L}$ droplet of DI water was placed on each specimen at a distance of $15 \mathrm{~mm}$ from the $\mathrm{I}_{3} \mathrm{~K}$ droplet (Figure 2A-B). After 3 $\mathrm{h}$ the droplets of DI water were collected and tested using UV-vis spectrophotometry (see example in Figure 2C). Absorbance at $288 \mathrm{~nm}$ was monitored which corresponded to the absorbance peak of $I_{3} \mathrm{~K}$; the stronger the signal the higher the $\mathrm{I}_{3} \mathrm{~K}$ concentration. The $\mathrm{I}_{3} \mathrm{~K}$ migration was additionally manifested by a gradual increase in brownish-red color in the membrane. It was observed that the migration was taking place only within the membranes since no traces of $\mathrm{I}_{3} \mathrm{~K}$ were noticed on the sample surfaces.

The slowest migration of $\mathrm{I}_{3} \mathrm{~K}$ was observed for the sample with $40 \mathrm{phr}$ of glycerol, as expected. As argued previously, at lower glycerol loadings the distances between glycerol droplets are relatively large, thus the mass transport phenomena progress slowly. ${ }^{31}$ Interestingly, the experiment revealed that the fastest migration of $\mathrm{I}_{3} \mathrm{~K}$ took place in a sample with $80 \mathrm{phr}$ of glycerol while the sample with $120 \mathrm{phr}$ allowed for slightly slower transport compared to $80 \mathrm{phr}$. The fastest migration was expected to take place through the glycerolsilicone matrix containing $120 \mathrm{phr}$ of glycerol that possesses a bicontinuous structure (at highest loadings of glycerol formation of interconnections between adjacent glycerol domains takes place thus creating glycerol channels (consecutive interconnected glycerol domains) throughout the membrane, which theoretically allow for fast mass transport). ${ }^{27,31}$ It is hypothesized that the mass transport rate through the glycerol-silicone membranes is governed by the content of glycerol having a two-fold impact. Firstly, the higher the glycerol loading the thinner the silicone separating the glycerol domains and hence the faster the diffusion. However, at high glycerol loadings the molecule migration is slowed down by diluting the system with higher volume of the liquid (the presence of water in the membrane 
will additionally influence the mass transport in a similar fashion). This hypothesis is valid only for small molecules (e.g., $\mathrm{I}_{3} \mathrm{~K}$ ) that can easily pass through the silicone. It is expected that larger molecules, such as proteins and polymers, will not migrate (or the migration will be very limited) through the membranes unless the matrix is very highly swollen by large quantities of water in the membrane, which significantly widens the glycerol channels. We hypothesize that the mass transport throughout the glycerol-silicone elastomers and its selective permeability could be used in producing semi-permeable valves for substance separation in microfluidic devices.
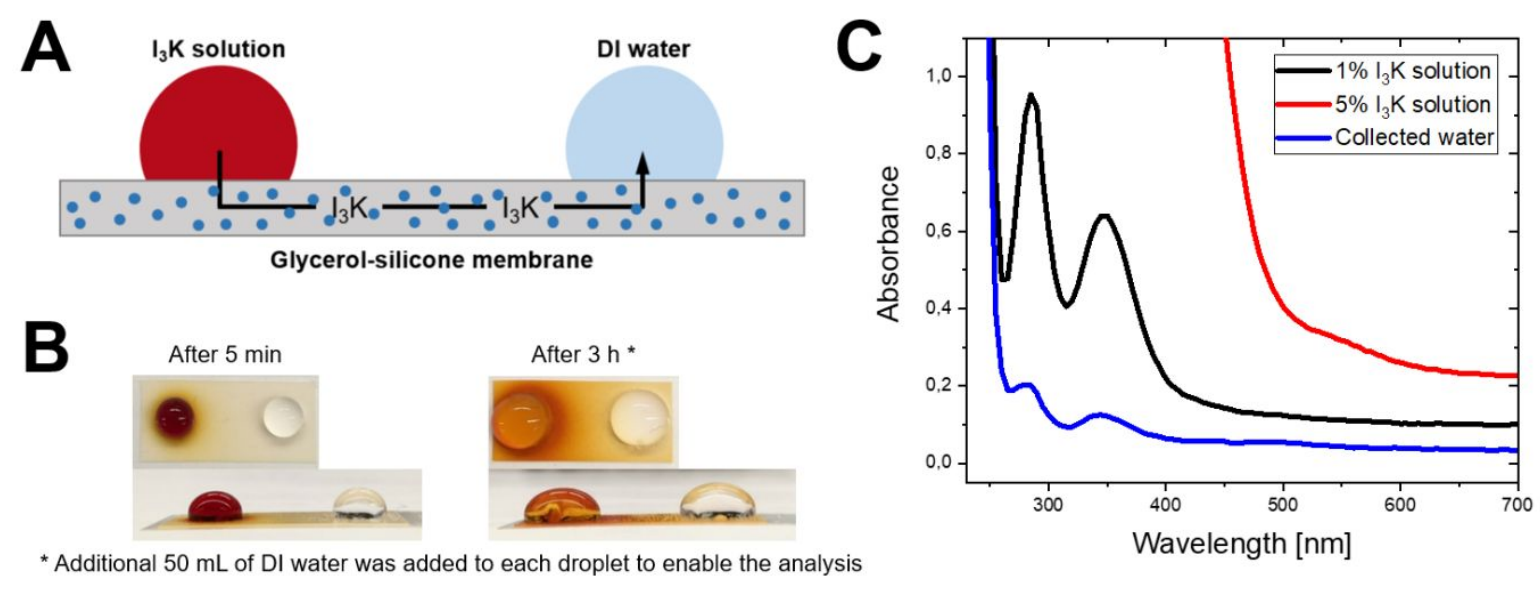

Figure 2. (A) Scheme of an experiment depicting migration of small molecules (e.g. $I_{3} \mathrm{~K}$ ) through the glycerol-silicone membrane. The mass transport is driven by the diffusion processes. (B) Top and side view of a $5 \% \mathrm{I}_{3} \mathrm{~K}$ water solution droplet (left) and water droplet placed on a silicone membrane containing $120 \mathrm{phr}$ of glycerol. The spreading of color is attributed to the $\mathrm{I}_{3} \mathrm{~K}$ migration through the membrane. (C) UV-vis spectra of droplets collected from the surface of the membrane. $50 \mathrm{~mL}$ of DI water was added to each droplet to enable the analysis. 


\subsection{Enzymatic reactions using TRY- and CHT-charged glycerol-silicone membranes}

The hydrolysis of BAEE mediated by TRY, or BTEE mediated by CHT (Figure 3A) were chosen as model systems to evaluate the performance of the glycerol-silicone membranes as hosts for enzymatic reactions. SEM images of cross-sections of elastomer samples made with $80 \mathrm{phr}$ of glycerol - with and without chymotrypsin - indicated that the presence of enzymes in the glycerol in the investigated range did not influence the morphology of the glycerolsilicone elastomers (see Figure 3B-C). The membranes $(9 \times 70 \mathrm{~mm})$ were placed on plastic supports and were transferred into quartz cuvettes which were subsequently filled with aqueous substrate solutions $(0.015 \mathrm{wt} \%$ in DI water). The cuvettes were tightly sealed to eliminate water evaporation (the membrane was physically fixed within the cuvette, Figure 3D), placed in a spectrophotometer and the progress of the enzymatic reaction carried out at room temperature was monitored by tracking changes in the absorbance at wavelengths of $253 \mathrm{~nm}$ and $256 \mathrm{~nm}$ for BAEE and BTEE, respectively. ${ }^{43,44}$ Trypsin and chymotrypsin did not absorb light in the investigated wavelength range, therefore any eventual leaching did not influence the measurements.

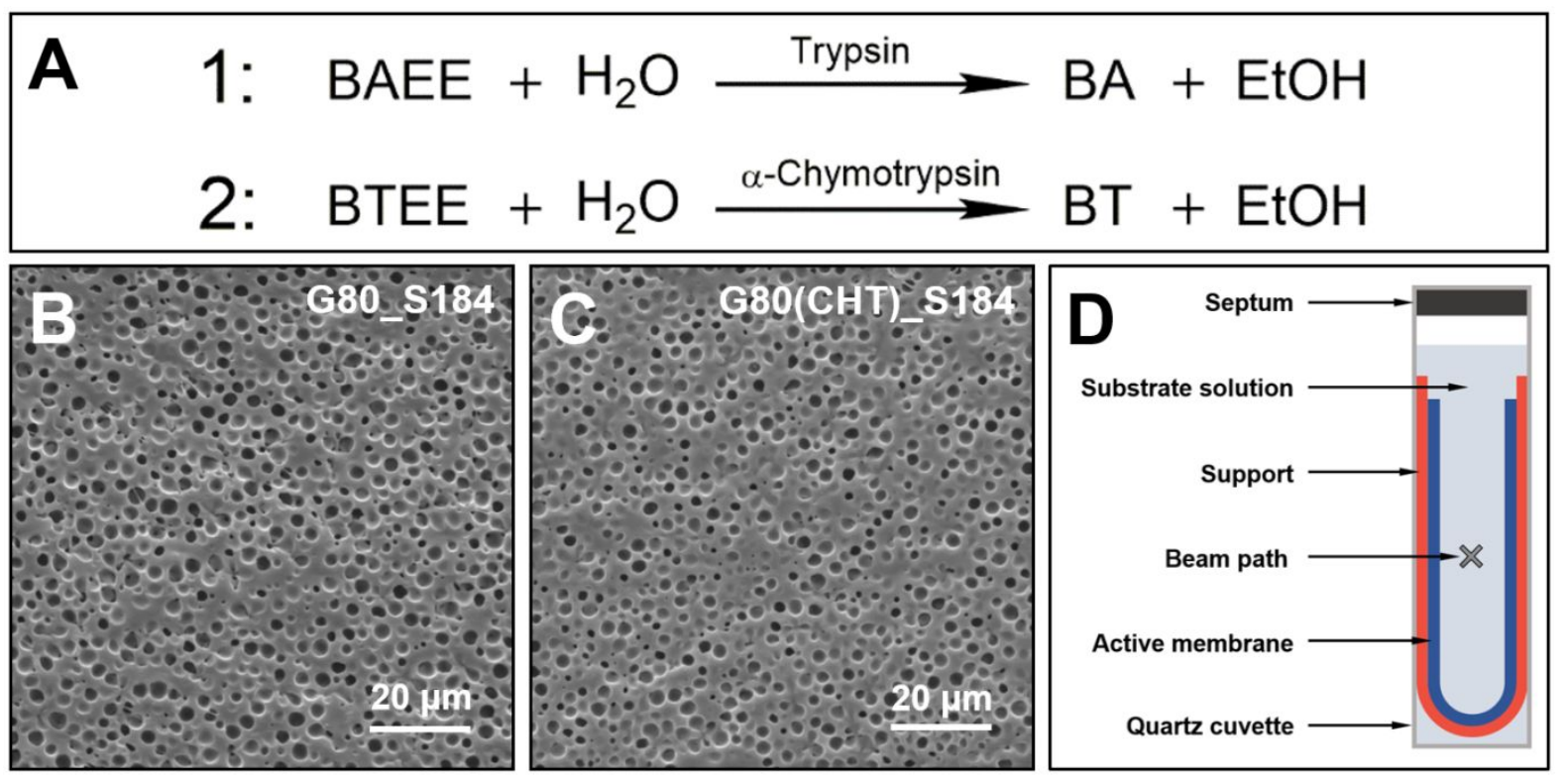


Figure 3. (A) Biochemical reaction equations of TRY/BAEE and CHT/BTEE systems. (BC) SEM images of cross-sections of glycerol-silicone elastomers without and with incorporated chymotrypsin. (D) Schematic illustration of the experimental setup used for evaluating biochemical reactions by means of UV-vis spectrophotometry.

Firstly, the conversion of BAEE was investigated. An increase in absorbance corresponding to the progress of the enzymatic reaction was observed already after $1-2$ minutes after initiation of the experiment and the maximum relative conversion (calculated based on results obtained in a control experiment presented in the Supplementary Information, Figure S7) was achieved after approximately $30-40 \mathrm{~min}$ (Figure 4A). The behavior of the CHT/BTEE system was quite different. The results indicated a slight decrease in absorbance taking place in the first 20 min of the process (Figure 4B). This is most likely related to the slow diffusion of BTEE into and within the membrane caused by the hydrophobic nature of BTEE, relatively slow conversion due to low amounts of active units per mg of the enzyme, and the slow release of the product, which ultimately leads to a decrease of the BTEE concentration in the substrate solution. Subsequently, the absorbance increased, which revealed that the reaction product was being released from the membrane. The sample reached a maximum product concentration at about $180 \mathrm{~min}$, after which no further increase in absorbance was observed. The experiments suggested that, as expected, the overall rates of the biocatalytic processes using the glycerol-silicone membranes are different for different enzyme-substrate pairs and are strongly species specific and therefore each case has to be evaluated individually.

Subsequently, samples with 40, 80 and $120 \mathrm{phr}$ of glycerol charged with the same content of trypsin (the amount of the enzyme per mass unit of the membrane was identical) were 
investigated for their capacity to hydrolyze BAEE. The UV-vis spectrophotometry results presented in Figure 4C indicate that the slowest BAEE hydrolysis was obtained using the composition with $40 \mathrm{phr}$ of glycerol. The compositions with moderate (80 phr) and high (120 phr) glycerol content exhibited higher performance in terms of product conversion and release compared to $40 \mathrm{phr}$. Discharge of the hydrolysis product was slightly faster in sample with $80 \mathrm{phr}$ of glycerol compared to $120 \mathrm{phr}$. These results are consistent with those discussed in Section 3.2. The study suggests that the transport-accelerating effect of decreasing silicone spacing between adjacent glycerol domains is outcompeted by the dilution effect caused by the higher glycerol loadings. Thus, the most efficient mass transport was observed for the sample with 80 phr of glycerol.
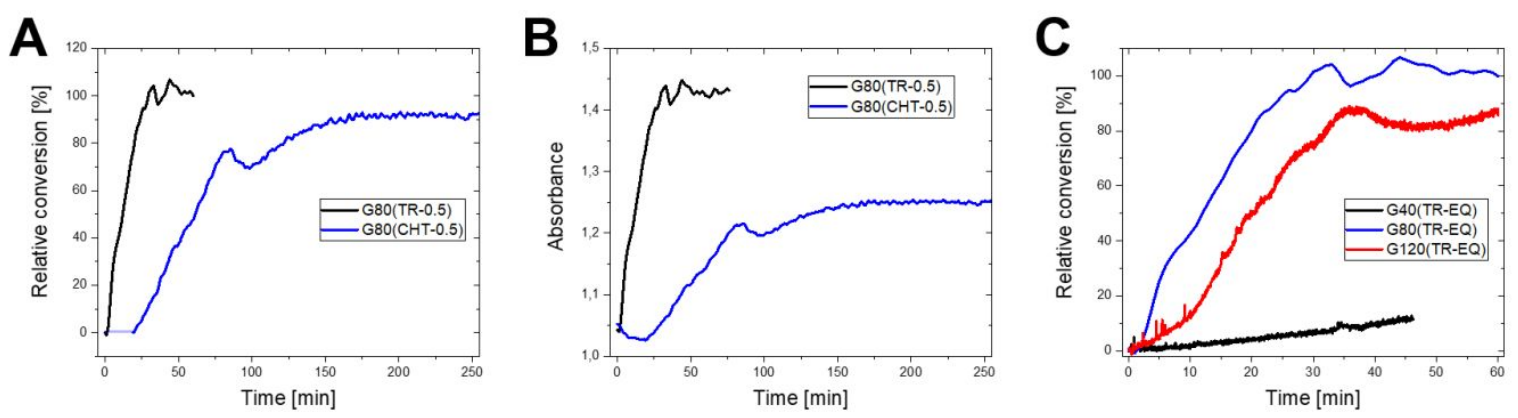

Figure 4. (A) Relative conversion of BAEE and BTEE using TR- and CHT-charged glycerol-silicone membranes, respectively. (B) Changes of absorbance registered during the conversion of BAEE and BTEE using TR- and CHT-charged glycerol-silicone membranes, respectively. (C) Relative conversion of BAEE using TR-charged glycerol-silicone membranes containing 40, 80 and 120 phr of glycerol.

\subsection{Colorimetric sensing of glucose}

The field of electronic biosensors is rapidly developing in research areas such as the sensing of body fluids, meat spoilage, and pesticides. ${ }^{45-50}$ While enzyme-based colorimetric methods are less common, they are gaining importance due to recent developments in research on 
sensory microfluidic devices for in-vivo monitoring of body fluids. ${ }^{51}$ Here, based on the results above, we present a facile, yet powerful, platform for creating colorimetric bioassays entrapped in a flexible and robust polymeric membrane.

\subsubsection{Colorimetric glucose detection}

A two-enzyme cascade reaction glucose detection assay was incorporated into the glycerolsilicone membrane (referred to as the glycerol-silicone glucose assay, GSGA). In this tworeaction process glucose is oxidized by GOx (glucose oxidase) to gluconic acid with concomitant formation of hydrogen peroxide as one of the products. Subsequently, the hydrogen peroxide is reduced to water by HPR (horseradish peroxidase) while iodide is oxidized to iodine, which results in a color change from transparent and colorless to yellow/brown (see Figure 5A). ${ }^{51-53}$ Each glycerol droplet acts as a microreactor containing the glucose assay cocktail: GOx, HPR, KI, water and trehalose, which in this assay is a required stabilizer for the enzymes. Details on the optimization of the "enzyme cocktail" can be found in the Supporting Information, Section S5.

A typical glucose detection experiment is presented in Figure 5B. Glucose was delivered to the elastomer system in the form of water solutions of different concentrations. For example, $50 \mu \mathrm{L}$ droplets of glucose solutions (20, 5 and $1 \%$ in water) were dispensed on $13 \times 13 \times 0.1$ mm GSGA specimens and allowed to react for 2, 20, 40, 60, 80, and 100 min, respectively. DI water was dispensed on the GSGA specimens for reference and kept for 2, 50 and 100, min. All experiments were carried out at room temperature. Figures 5C-E present the test setup before, after reaction, and following removal of the remaining glucose solution droplet, respectively. The image of the experiment setup obtained after a thorough washing and drying was then used to analyze the color intensity obtained on each square specimen. The 
color at the center of each of the 21 specimens was transferred onto a colorimetric diagram using an image processing tool. The colorimetric diagram is presented in Figure $5 \mathrm{~F}$ and a more detailed color analysis can be found in the Supporting Information, Figure S11.

It is clear that the two-stage enzymatic process using GSGA membrane works efficiently. The color intensity, and thus the reaction progress, depended on the reaction time as well as the glucose concentration. The longer the experimental time, the higher amount of glucose could diffuse to the glycerol compartments and initiate the cascade reaction. The evolution of color was observed after only $2 \mathrm{~min}$, which indicates a substantial diffusion rate of glucose to the membrane and high efficiency of the enzymatic reactions, which implies that migration of highly polar, glycerol soluble substrates/products is a key to high process practicality and efficacy. The color becomes more intense as the process time became longer and reached a maximum after $100 \mathrm{~min}$. A parallel experiment indicated no further color change for experiments lasting longer than $100 \mathrm{~min}$.

The experiments indicated that the most intense color change was observed for glucose concentrations of $1 \%$ while the least intense signals were observed with glucose concentrations of $20 \%$, which is counterintuitive. The slower processing at higher substrate concentrations might be caused by the higher viscosity of the $20 \%$ glucose solution (1.95 mPa.s at $20{ }^{\circ} \mathrm{C}$ ) compared to $5 \%$ and $1 \%$ solutions (around $1 \mathrm{mPa}$.s at $20{ }^{\circ} \mathrm{C}$ ), which inevitably leads to lower diffusion rates and thus slower color change. ${ }^{54}$ As the process continues, water and glucose migrate into the membrane and so the viscosity of the droplets with higher glucose concentration will increase substantially faster compared to droplets with less glucose. This will certainly magnify the deceleration of the glucose migration even further. In a follow-up study, to better understand the process, the color change using low 
concentration glucose solutions $(0.1,0.01$ and $0.001 \%)$ was investigated. In all cases, the color change was less significant compared to the $1 \%$ solution and was found to decrease as the concentration was lowered, as expected. No color change was observed for the concentration of $0.001 \%$, which defines the glucose detection limit for this particular formulation. Nevertheless, the color change at the glucose concentration as low as $0.01 \%$ was obvious and increased gradually with increasing reaction time up to 100 minutes. More details can be found in the Supporting Information, Figure S9 and Figure S10.

One can hypothesize that such an assay could be used as a skin patch for detecting glucose concentration in sweat for patients suffering from hyperglycemia. Glucose levels in sweat of hyperglycemic patients reach concentrations as high as $0.02 \mathrm{wt} \%$, which is well above the detection limit of these membranes. ${ }^{55-57}$ Therefore, this product could act as a very simple and cost-efficient sweat absorbing patch that warns of high glucose levels in the perspiration of hyperglycemic patients. ${ }^{51,56,58}$ In addition, the GSGA (or membranes containing similar assays detecting other low molecular weight compounds) could be utilized for the fabrication of components of 3D microfluidic devices detecting the presence of glucose in the investigated liquid. 


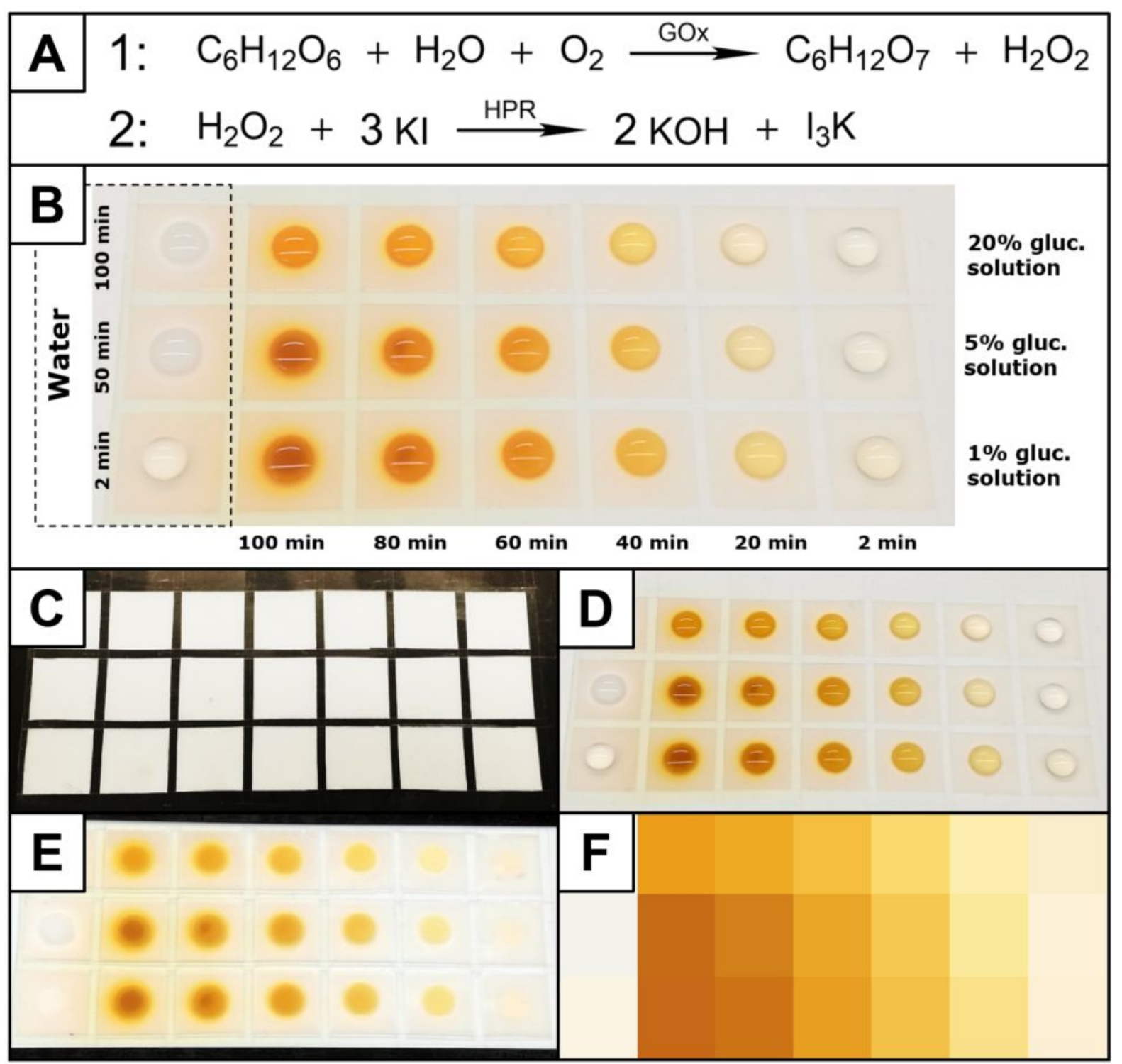

Figure 5. (A) Scheme of a two-reaction glucose assay catalyzed by GOx and HPR. (B) Colorimetric experiment in which the glycerol-silicone membranes (every 13x13 mm square) was charged with an enzyme cocktail of a glucose assay. Droplets of $50 \mu \mathrm{L}$ of various glucose solutions $(20,5$ and $1 \%$ ) were dispensed on squared specimens. The glucose assay platform exhibited a time-dependent color evolution related to progress of the reaction. (C) Experimental setup before the experiment. (D) Experimental setup at the end of the experiment. (E) Experimental setup after washing and drying. (F) Colorimetric diagram obtained by evaluating colors of the experimental setup after washing and drying. 


\subsubsection{Evaluation of the glucose assay conversion rate}

Similar to the TRY/BAEE and CHY/BTEE systems, the GSGA membranes were investigated in terms of the progress of the enzymatic reaction using the UV-vis spectrophotometer and the normalized iodine release curves are presented in Figure 6. Here two specimens based on a membrane containing $120 \mathrm{phr}$ of glycerol were submerged in 0.1 $\%$ and $10 \%$ aqueous glucose solutions, respectively, demonstrating that assays using the glycerol/silicone matrix in both air or water are viable. The progress of the reactions was monitored by tracking changes of the bulk solution absorbance at $288 \mathrm{~nm}$, which corresponds to one of the absorbance peaks of iodine. No products were released from the membranes into either solution in the first $10 \mathrm{~min}$. It was assumed that during this phase the first glucose molecules diffused into the membrane, the two-stage enzymatic reaction took place and the iodine (the monitored substance) was released. After the induction period the process became continuous until one of the substrates was depleted. In this case glucose was used in excess, therefore the process ran until no more potassium iodide was available in the membrane. Interestingly, the final relative conversion (presented in Figure 6A) was lower than expected based results obtained in the control experiment (see Supporting Information, Figure S12). Both membranes were investigated after the experiment and a significant color change was observed (see Figure 6B), which indicated that a significant amount of generated iodine remained trapped in the GSGA membrane. However, no color change was observed by eye in the external reaction solution most likely due to a significant dilution of iodine.

The results presented in Figure 6 indicate that the glucose concentration in the process environment significantly influences the generation and release rate of iodine. The higher the amount of glucose in the solution, the more efficient the diffusion of glucose into the membrane and thereby the faster iodine release is achieved. Importantly, in both experiments 
a constant (zero-order) release rate of iodine was observed after an induction period, which is in a good agreement with the results reported previously that suggest that the silicones containing $120 \mathrm{phr}$ of glycerol release active substances with a constant rate throughout the whole process with no initial burst. ${ }^{31}$ These results are especially interesting from the perspective of drug delivery systems where a constant dose of an active substance is a critical parameter.

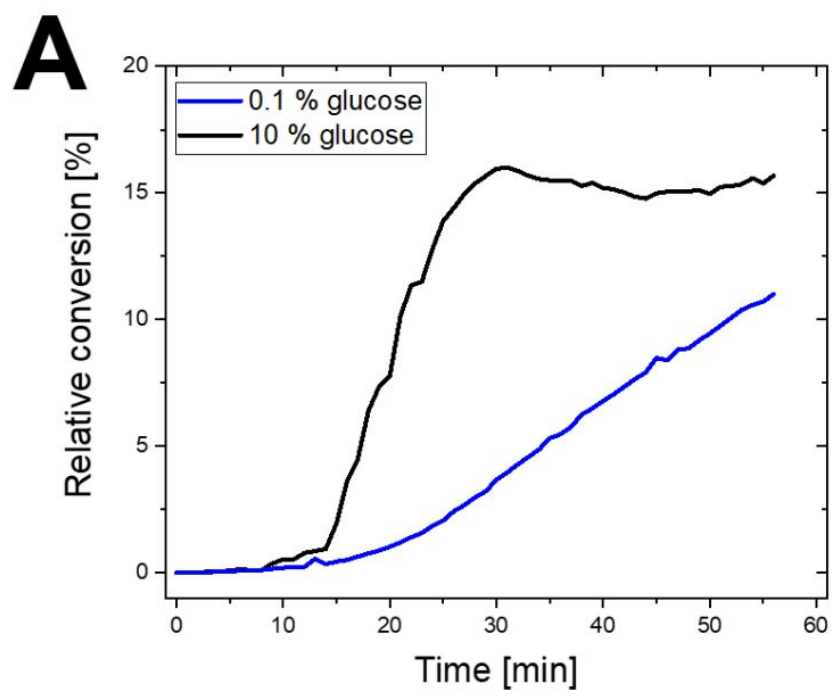

B

Figure 6. (A) Progress of the two-step cascade biochemical reaction (normalized curves) in the glycerol-silicone glucose assay membranes using $0.1 \%$ and $10 \%$ glucose solutions. Iodine was discharged following the zero-order kinetics. (B) Water-rinsed and blow-dried strip of the GSGA membrane (120 phr of glycerol) after the test performed using a UV-vis spectrophotometer. Note that a substantial amount of $\mathrm{I}_{3} \mathrm{~K}$ remaining in the specimen after the experiment.

\section{Conclusions}

An atypical method of physical entrapment of enzymes within soft and stretchable membranes was developed. Enzymes were incorporated into glycerol domains of glycerolsilicone elastomers. The TRY-mediated conversion of BAEE and CHT-mediated conversion 
of BTEE were successfully conducted proving a great potential of this technology as an enzyme carrier for conducting biochemical reactions. Importantly the enzymes were proven to be permanently encapsulated inside the silicone elastomer. Moreover, a colorimetric glucose assay enzyme cocktail was successfully incorporated and the membrane and was proved to efficiently detect glucose in water solutions even at concentrations as low as 0.01 $\%$, which potentially enables the application of this technology to the detection of alarming glucose levels in sweat of hyperglycemic individuals. Additionally, the mobility of small molecules within the high-glycerol loading membranes was confirmed; small molecules migrate throughout the elastomer in order to balance the concentration in the entire bulk of a specimen. Moreover, the proposed technology could be used as a basis for microfluidic bioreactors while the GSGA, or similar assays, can be used as colorimetric sensors within microfluidic devices.

\section{Supporting Information}

Detailed composition of investigated samples, description of formation of bicontinuous structure, SEM images, chemical formulas of BAEE and BTEE, control experiments for glucose assay, TRY/BAEE and CHY/BTEE systems, details on colorimetric glucose assay.

\section{ORCID}

Piotr Mazurek: 0000-0002-8055-2766

Paul M. Zelisko: 0000-0002-3770-2562

Anne L. Skov: 0000-0003-1223-6638

Michael A. Brook: 0000-0003-0705-9657

\section{Acknowledgements}


The authors acknowledge the generous funding from Danmarks Frie Forskningsfond (grant number 7017-00124A). The authors are also grateful to Otto Mønsted Foundation Denmark (grant number 18-70-1319) for financial support made possible the collaboration between Technical University of Denmark, McMaster University and Brock University, and the Natural Sciences and Engineering Council (NSERC) of Canada for additional financial support (grant numbers: RGPIN-2018-04439, RGPIN-2016-05793).

\section{Notes}

The authors declare no competing financial interest.

\section{References:}

(1) Garcia-Galan, C.; Berenguer-Murcia, Á.; Fernandez-Lafuente, R.; Rodrigues, R. C. Potential of Different Enzyme Immobilization Strategies to Improve Enzyme Performance. Adv. Synth. Catal. 2011, 353, 2885-2904.

(2) Sheldon, R. A.; van Pelt, S. Enzyme Immobilisation in Biocatalysis: Why, What and How. Chem. Soc. Rev. 2013, 42, 6223-6235.

(3) Budžaki, S.; Miljić, G.; Sundaram, S.; Tišma, M.; Hessel, V. Cost Analysis of Enzymatic Biodiesel Production in Small-Scaled Packed-Bed Reactors. Appl. Energy 2018, 210, 268-278.

(4) Mehta, J.; Bhardwaj, N.; Bhardwaj, S. K.; Kim, K. H.; Deep, A. Recent Advances in Enzyme Immobilization Techniques: Metal-Organic Frameworks as Novel Substrates. Coord. Chem. Rev. 2016, 322, 30-40.

(5) Hoffmann, C.; Chiaula, V.; Yu, L.; Pinelo, M.; Woodley, J. M.; Daugaard, A. E. Simple Preparation of Thiol-Ene Particles in Glycerol and Surface Functionalization 
by Thiol-Ene Chemistry (TEC) and Surface Chain Transfer Free Radical Polymerization (SCT-FRP). Macromol. Rapid Commun. 2018, 39, 1-6.

(6) Hoffmann, C.; Pereira Rosinha Grundtvig, I.; Thrane, J.; Garg, N.; Gernaey, K. V.;

Pinelo, M.; Woodley, J. M.; Krühne, U.; Daugaard, A. E. Experimental and Computational Evaluation of Area Selectively Immobilized Horseradish Peroxidase in a Microfluidic Device. Chem. Eng. J. 2018, 332, 16-23.

(7) Yong, J. K. J.; Stevens, G. W.; Caruso, F.; Kentish, S. E. The Use of Carbonic Anhydrase to Accelerate Carbon Dioxide Capture Processes. J. Chem. Technol. Biotechnol. 2015, 90, 3-10.

(8) Frampton, M. B.; Zelisko, P. M. Synthesis of Lipase-Catalysed Silicone-Polyesters and Silicone-Polyamides at Elevated Temperatures. Chem. Commun. 2013, 49, 9269-9271.

(9) Hanefeld, U.; Gardossi, L.; Magner, E. Understanding Enzyme Immobilisation. Chem. Soc. Rev. 2009, 38, 453-468.

(10) Conte, M. P.; Lau, K. H. A.; Ulijn, R. V. Biocatalytic Self-Assembly Using Reversible and Irreversible Enzyme Immobilization. ACS Appl. Mater. Interfaces 2017, 9, 32663271.

(11) Rodrigues, R. C.; Ortiz, C.; Berenguer-Murcia, Á.; Torres, R.; Fernández-Lafuente, R. Modifying Enzyme Activity and Selectivity by Immobilization. Chem. Soc. Rev. 2013, $42,6290-6307$.

(12) Damnjanović, J. J.; Žuža, M. G.; Savanović, J. K.; Bezbradica, D. I.; Mijin, D. Ž.; Bošković-Vragolović, N.; Knežević-Jugović, Z. D. Covalently Immobilized Lipase Catalyzing High-Yielding Optimized Geranyl Butyrate Synthesis in a Batch and Fluidized Bed Reactor. J. Mol. Catal. B Enzym. 2012, 75, 50-59. 
(13) Yilmaz, E.; Can, K.; Sezgin, M.; Yilmaz, M. Immobilization of Candida Rugosa Lipase on Glass Beads for Enantioselective Hydrolysis of Racemic Naproxen Methyl Ester. Bioresour. Technol. 2011, 102, 499-506.

(14) Górecka, E.; Jastrzębska, M. Immobilization Techniques And Biopolymer Carriers - A Review. Biotechnol. Food Sci. 2011, 75, 27-34.

(15) Sheldon, R. A. Enzyme Immobilization: The Quest for Optimum Performance. $A d v$. Synth. Catal. 2007, 349, 1289-1307.

(16) Luo, J.; Meyer, A. S.; Mateiu, R. V.; Kalyani, D.; Pinelo, M. Functionalization of a Membrane Sublayer Using Reverse Filtration of Enzymes and Dopamine Coating. ACS Appl. Mater. Interfaces 2014, 6, 22894-22904.

(17) Zhang, H.; Zhang, H.; Luo, J.; Wan, Y. Enzymatic Cascade Catalysis in a Nanofiltration Membrane: Engineering the Microenvironment by Synergism of Separation and Reaction. ACS Appl. Mater. Interfaces 2019, 11, 22419-22428.

(18) Mohamad, N. R.; Marzuki, N. H. C.; Buang, N. A.; Huyop, F.; Wahab, R. A. An Overview of Technologies for Immobilization of Enzymes and Surface Analysis Techniques for Immobilized Enzymes. Biotechnol. Biotechnol. Equip. 2015, 29, 205220.

(19) Liang, K.; Coghlan, C. J.; Bell, S. G.; Doonan, C.; Falcaro, P. Enzyme Encapsulation in Zeolitic Imidazolate Frameworks: A Comparison between Controlled CoPrecipitation and Biomimetic Mineralisation. Chem. Commun. 2015, 52, 473-476.

(20) Chang, F. P.; Hung, Y.; Chang, J. H.; Lin, C. H.; Mou, C. Y. Enzyme Encapsulated Hollow Silica Nanospheres for Intracellular Biocatalysis. ACS Appl. Mater. Interfaces 2014, 6, 6883-6890. 
(21) Avnir, D.; Lev, O.; Livage, J. Recent Bio-Applications of Sol-Gel Materials. J. Mater. Chem. 2006, 16, 1013-1030.

(22) Avnir, D.; Braun, S.; Lev, O.; Ottolenghi, M. Enzymes and Other Proteins Entrapped in Sol-Gel Materials. Chem. Mater. 1994, 6, 1605-1614.

(23) Frenkel-Mullerad, H.; Avnir, D. Sol - Gel Materials as Efficient Enzyme Protectors : Preserving the Activity of Phosphatases under Extreme PH Conditions. J. Am. Chem. Soc. 2005, 127, 8077-8081.

(24) Cruz-Aguado, J. A.; Chen, Y.; Zhang, Z.; Elowe, N. H.; Brook, M. A.; Brennan, J. D. Ultrasensitive ATP Detection Using Firefly Luciferase Entrapped in Sugar-Modified Sol-Gel-Derived Silica. J. Am. Chem. Soc. 2004, 126, 6878-6879.

(25) Shen, Q.; Yang, R.; Hua, X.; Ye, F.; Zhang, W.; Zhao, W. Gelatin-Templated Biomimetic Calcification for $\beta$-Galactosidase Immobilization. Process Biochem. 2011, $46,1565-1571$

(26) Won, K.; Kim, S.; Kim, K. J.; Park, H. W.; Moon, S. J. Optimization of Lipase Entrapment in Ca-Alginate Gel Beads. Process Biochem. 2005, 40, 2149-2154.

(27) Mazurek, P.; Hvilsted, S.; Skov, A. L. Green Silicone Elastomer Obtained from a Counterintuitively Stable Mixture of Glycerol and PDMS. Polymer 2016, 87, 1-7.

(28) Mazurek, P.; Yu, L.; Gerhard, R.; Wirges, W.; Skov, A. L. Glycerol as HighPermittivity Liquid Filler in Dielectric Silicone Elastomers. J. Appl. Polym. Sci. 2016, $133,1-8$.

(29) Zelisko, P. M.; Flora, K. K.; Brennan, J. D.; Brook, M. A. Water-in-Silicone Oil Emulsion Stabilizing Surfactants Formed from Native Albumin and $\alpha, \omega-$ Triethoxysilylpropyl-Polydimethylsiloxane. Biomacromolecules 2008, 9, 2153-2161. 
(30) Mazurek, P.; Ekbrant, B. E. F.; Madsen, F. B.; Yu, L.; Skov, A. L. Glycerol-Silicone Foams - Tunable 3-Phase Elastomeric Porous Materials. Eur. Polym. J. 2019, 113, $107-114$.

(31) Mazurek, P.; Brook, M. A.; Skov, A. L. Glycerol-Silicone Elastomers as Active Matrices with Controllable Release Profiles. Langmuir 2018, 34, 11559-11566.

(32) Bartzoka, V.; McDermott, M. R.; Brook, M. A. Protein-Silicone Interactions. Adv. Mater. 1999, 11, 257-259.

(33) Okada, T.; Ikada, Y. Tissue Reactions to Subcutaneously Implanted, Surface-Modified Silicones. J. Biomed. Mater. Res. 1993, 27, 1509-1518.

(34) Orçaire, O.; Buisson, P.; Pierre, A. C. Application of Silica Aerogel Encapsulated Lipases in the Synthesis of Biodiesel by Transesterification Reactions. J. Mol. Catal. B Enzym. 2006, 42, 106-113.

(35) Zelisko, P. M.; Brook, M. A. Stabilization of $\alpha$-Chymotrypsin and Lysozyme Entrapped in Water-in-Silicone Oil Emulsions. Langmuir 2002, 18, 8982-8987.

(36) Zelisko, P. M.; Aguilar, A. L.; Brook, M. A. Delivery of Both Active Enzyme and Bleach from Water-in-Silicone Oil (D4) Emulsions. Langmuir 2007, 23, 3620-3625.

(37) Ragheb, A.; Brook, M. A.; Hrynyk, M. Highly Activated, Silicone Entrapped, Lipase. Chem. Commun. 2003, 3, 2314-2315.

(38) Wiemann, L. O.; Nieguth, R.; Eckstein, M.; Naumann, M.; Thum, O.; AnsorgeSchumacher, M. B. Composite Particles of Novozyme 435 and Silicone: Advancing Technical Applicability of Macroporous Enzyme Carriers. ChemCatChem 2009, 1, $455-462$.

(39) Vagenende, V.; Yap, M. G. S.; Trout, B. L. Mechanisms of Protein Stabilization and 
Prevention of Protein Aggregation by Glycerol. Biochemistry 2009, 48, 11084-11096.

(40) Pazhang, M.; Mehrnejad, F.; Pazhang, Y.; Falahati, H.; Chaparzadeh, N. Effect of Sorbitol and Glycerol on the Stability of Trypsin and Difference between Their Stabilization Effects in the Various Solvents. Biotechnol. Appl. Biochem. 2016, 63, 206-213.

(41) Gekko, K.; Timasheff, S. N. Mechanism of Protein Stabilization by Glycerol: Preferential Hydration in Glycerol-Water Mixtures. Biochemistry 1981, 20, 46674676.

(42) Mazurek, P.; Vudayagiri, S.; Skov, A. L. How to Tailor Flexible Silicone Elastomers with Mechanical Integrity: A Tutorial Review. Chem. Soc. Rev. 2019, 48, 1448-1464.

(43) Vandermeers, A.; Vandermeers-Piret, M. C.; Rathé, J.; Christophe, J. Simple Automated Spectrophotometric Method for Assay of Trypsin and Chymotrypsin in Duodenal Juice. Clin. Chem. 1972, 18, 1514-1517.

(44) Hummel, B. C. W. A Modified Spectrophotometric Determination of Chymotrypsin, Trypsin, and Thrombin. Can. J. Biochem. Physiol. 1959, 37, 1393-1399.

(45) Corrie, S. R.; Coffey, J. W.; Islam, J.; Markey, K. A.; Kendall, M. A. F. Blood, Sweat, and Tears: Developing Clinically Relevant Protein Biosensors for Integrated Body Fluid Analysis. Analyst 2015, 140, 4350-4364.

(46) Matzeu, G.; Florea, L.; Diamond, D. Advances in Wearable Chemical Sensor Design for Monitoring Biological Fluids. Sensors Actuators B. Chem. 2015, 211, 403-418.

(47) Mohebi, E.; Marquez, L. Intelligent Packaging in Meat Industry: An Overview of Existing Solutions. J. Food Sci. Technol. 2015, 52, 3947-3964.

(48) Singh, P. K.; Jairath, G.; Ahlawat, S. S.; Pathera, A.; Singh, P. Biosensor: An 
Emerging Safety Tool for Meat Industry. J. Food Sci. Technol. 2016, 53, 1759-1765.

(49) Van Dyk, J. S.; Pletschke, B. Review on the Use of Enzymes for the Detection of Organochlorine, Organophosphate and Carbamate Pesticides in the Environment. Chemosphere 2011, 82, 291-307.

(50) Pinyou, P.; Blay, V.; Muresan, L. M.; Noguer, T. Enzyme-Modified Electrodes for Biosensors and Biofuel Cells. Mater. Horizons 2019, 6, 1336-1358.

(51) Koh, A.; Kang, D.; Xue, Y.; Lee, S.; Pielak, R. M.; Kim, J.; Hwang, T.; Min, S.; Banks, A.; Bastien, P.; Manco, M. C.; Wang, L.; Ammann, K. R.; Jang, K. I.; Won, P.; Han, S.; Ghaffari, R.; Paik, U.; Slepian, M. J.; Balooch, G.; Huang, Y.; Rogers, J. A. A Soft, Wearable Microfluidic Device for the Capture, Storage, and Colorimetric Sensing of Sweat. Sci. Transl. Med. 2016, 8, 1-14.

(52) Martinez, A. W.; Phillips, S. T.; Carrilho, E.; Iii, S. W. T.; Sindi, H.; Whitesides, G. M.; Thomas, S. W.; Sindi, H.; Whitesides, G. M. Simple Telemedicine for Developing Regions: Camera Phones and Paper-Based Microfluidic Devices for Real-Time, OffSite Diagnosis. Anal. Chem. 2008, 80, 3699-3707.

(53) Peele, J. D.; Gadsden, R. H.; Crews, R. Semi-Automated vs. Visual Reading of Urinalysis Dipsticks. Clin. Chem. 1977, 23, 2242-2246.

(54) Telis, V. R. N.; Telis-Romero, J.; Mazzotti, H. B.; Gabas, A. L. Viscosity of Aqueous Carbohydrate Solutions at Different Temperatures and Concentrations. Int. J. Food Prop. 2007, 10, 185-195.

(55) Bruen, D.; Delaney, C.; Florea, L.; Diamond, D. Glucose Sensing for Diabetes Monitoring: Recent Developments. Sensors 2017, 17, 1-21.

(56) Lee, H.; Cho, H. R.; Kim, D. H.; Hyeon, T.; Hong, Y. S.; Choi, S. H.; Song, C.; Kang, 
T.; Shin, K.; Kim, M. S. Wearable/Disposable Sweat-Based Glucose Monitoring Device with Multistage Transdermal Drug Delivery Module. Sci. Adv. 2017, 3, 1-8.

(57) Moyer, J.; Ph, D.; Wilson, D.; Finkelshtein, I.; Wong, B.; Potts, R.; Ph, D. Correlation Between Sweat Glucose and Blood Glucose in Subjects with Diabetes. 2012, 14, 398402.

(58) Liu, Q.; Liu, Y.; Wu, F.; Cao, X.; Li, Z.; Alharbi, M.; Abbas, A. N.; Amer, M. R.; Zhou, C. Highly Sensitive and Wearable In2O3 Nanoribbon Transistor Biosensors with Integrated On-Chip Gate for Glucose Monitoring in Body Fluids. ACS Nano 2018, 12, 1170-1178. 


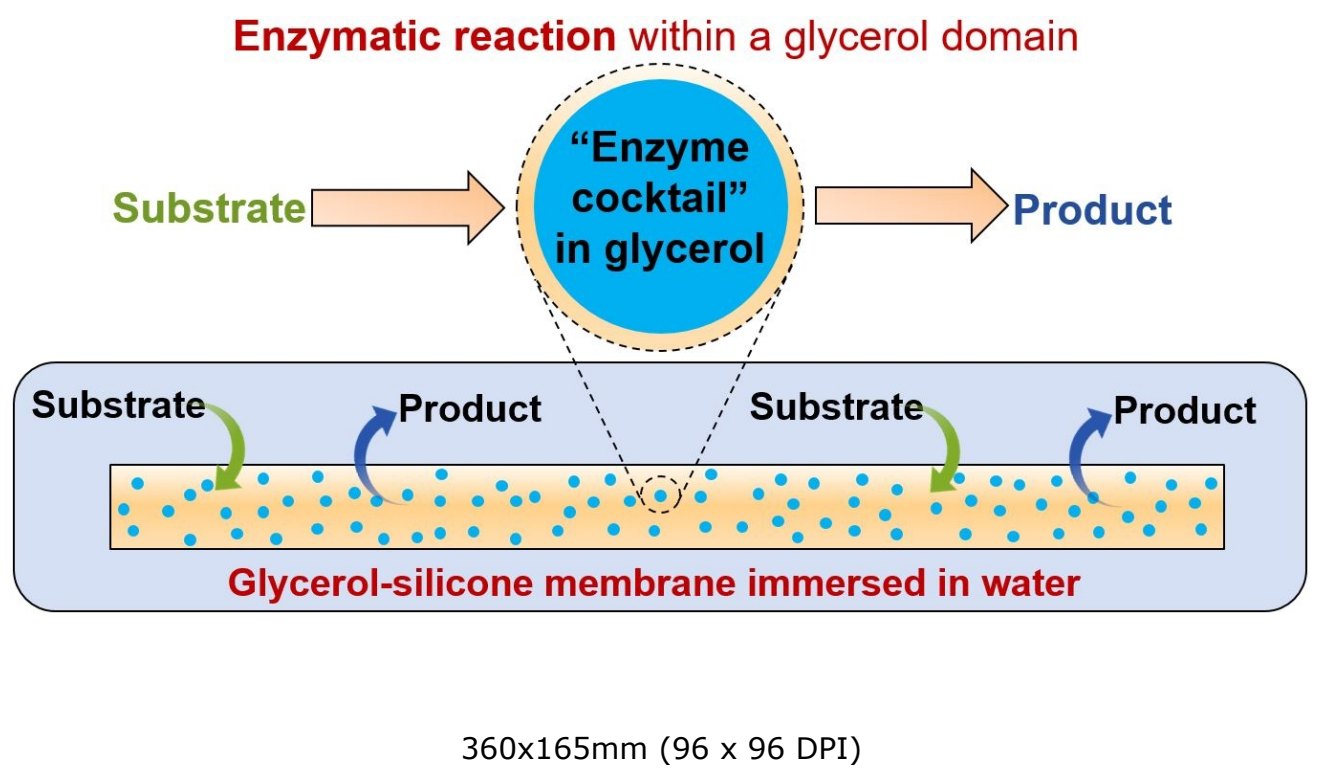

ACS Paragon Plus Environment 